\title{
Low-cost Instrument for Characterization of Solar Cells
}

\author{
Prakash Joshi \\ Department of Physic, Bhaktapur Multipal Campus \\ Email: joship7@gmail.com
}

\begin{abstract}
A low cost home-made instrument for characterization of solar cells has provided reliable data for drawing current versus voltage curves of the solar cells under test. The low cost instrument can be an alternative to high-cost standard instruments used for testing solar cells by determining light-to-electricity conversion efficiencies of the solar cells. Calibrations of commercially available mini-solar panels (silicon cells) with respect to a standard pyranometer (SolData) show that the mini-panels can measure solar radiation.
\end{abstract}

Key words: Solar cells, I-V curves, Characterization of solar cells, Light-to-electricity conversion efficiency

\section{BACKGROUND}

Solar energy is a renewable and clean source of energy and it is available all over the world at free cost. A solar cell converts light into electricity directly. Solar panels (often called photovoltaic or PV panels) can be installed nearby their users minimizing the cost required for transmission of the electricity from the panels to the users. Thus, PV panels are gaining popularity these days [1]. However, the electricity generated from PV panels is only about $0.1 \%$ of the electricity generated throughout the world; one of reasons of this negligibly small amount of the solar electricity is its higher price compared with the electricity generated from fossil fuels--conventional source of energy [2]. Efforts are being made to develop low-cost and efficient PV panels to reduce the cost of the solar electricity. Hence, extensive and intensive photovoltaic research activities are being carried out in various laboratories and research centers scattered in both developed and developing countries. In this regards, some institutes/research center in Nepal have initiated research on fabrication of dye-sensitized solar cells (DSCs). DSCs are considered as low cost and high efficiency solar cells [3].

The light-to-electricity conversion efficiency of a solar cell is defined as the ratio of the power density delivered by the solar cell to the power density of the incident light on the solar cell [4]. Performance of a solar cell is often evaluated by determining its efficiency; the efficiency of the solar cell can be measured by running an experiment using a solar simulator with a source meter in a laboratory. A solar simulator simulates solar spectrum at the laboratory and the solar cell under test is exposed to the stimulated solar spectrum [5]. The source meter generates variable voltages which are applied across the solar cell and the corresponding values of the current generated by the solar cell are simultaneously recorded along with the applied voltages. From the current (I) versus voltage (V) curve of the solar cell, the efficiency of the solar cell is calculated [6]. In order to accelerate photovoltaic research in Nepal, the photovoltaic laboratories should be well-equipped with standard instruments like solar simulators with source meters. However, commercially available such instruments are very expensive. For example, a solar simulator with a source meter from Solaronix (Sunirad A-45) costs about fifty thousand US dollars (personal communication, Sep 18 , 2013). The high cost of such instruments may cause unavailability of such instruments in the research laboratories which are running under low budgets in Nepal and the lack of such instruments may hinder the progress in photovoltaic research activities undertaken by such laboratories.

In this work, the author has presented a low-cost method for obtaining I-V curve of solar cells tested in natural sunlight following similar method reported by Steamtred [7]. Moreover, commercially available low-cost mini-solar panels were successfully calibrated as reference cells with respect to a standard pyranometer (SolData) so that the mini-solar panels can be used to measure the incident solar radiation on the device under test. The reliability of the lowcost instrument and method used to calculate efficiencies of solar cells were tested by comparing the measured efficiencies of the mini-panels with their standard values. 


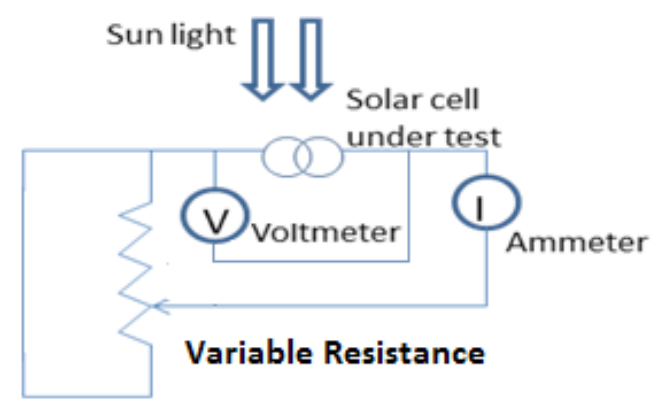

Figure 1: Circuit diagram of the home-made instrument used for characterization of solar cells by obtaining current versus voltage (I-V) curve.

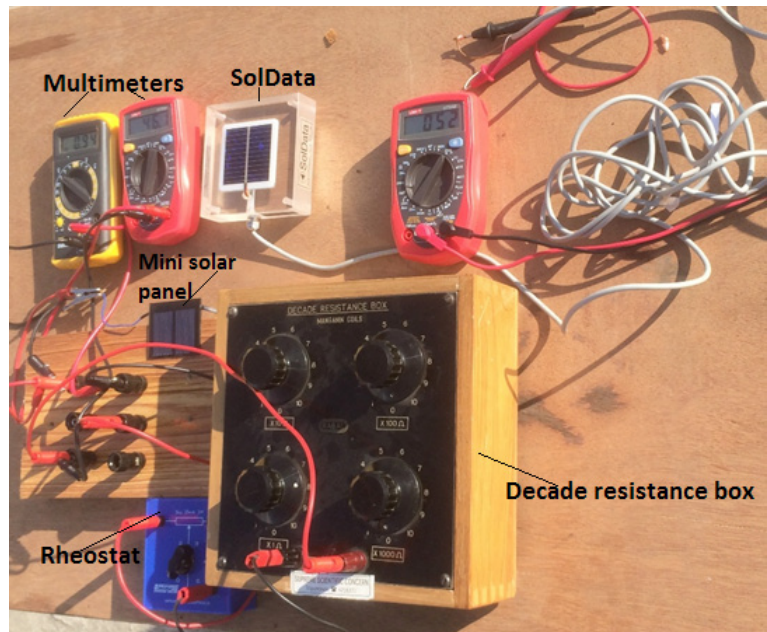

Figure 2: Photograph of the experimental set up for characterization of solar cells by obtaining current versus voltage (I-V) curve.

Figure 1 shows the circuit diagram of the home-made instrument used for characterization of solar cells by obtaining current versus voltage (I-V) curve. Figure 2 is the photograph of the experimental set up for characterization of solar cells by obtaining I-V curve. In order to test reliability of the testing instruments, commercially available mini-solar panels (Model: S1: SBE5949, S2: SBE5050, and S3: SBE7560) were purchased via ebay and they were used as solar cells under test [8-10]. Digital multimeters (UNi-T/UT33D, SZBJ/BM8320) were used as required voltmeter and ammeter for the circuit. Decade resistance box and rheostat were used as a variable resistance (load) across the solar cells under test. The device under the test (the mini- solar panels not dye-sensitized solar cells) were kept on a horizontal position, and the natural solar radiation was allowed to be incident on the mini- solar panels. The incident solar intensity (global radiation flux) on the solar panels was measured using SolData, commercially available pyranometer. In order to calculate the efficiencies of the solar cells in the natural solar radiation (without using a solar simulator), the intensity of input solar radiation is to be measured.

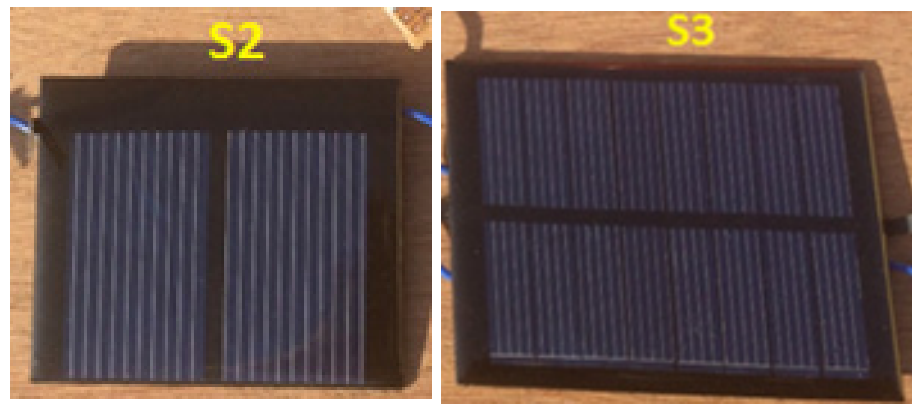

Figure 3: Photograph of commercially available mini-solar panels (Model: SBE5949, S2: SBE5050, and S3: SBE7560).

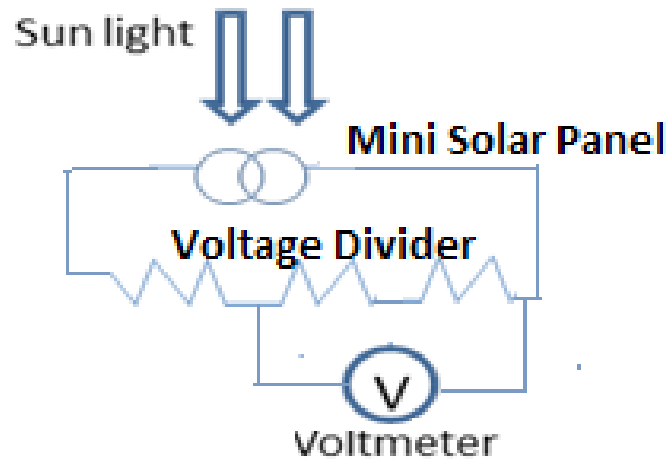

Figure 4: Circuit diagram for calibration of mini-solar panel (S1, S2, and S3) for measuring input solar radiation on solar cells.

This task was carried out at low-cost by using commercially available silicon based mini-solar panels (S1, S2, and S3; Figure 3 is the photograph of S2 and S3), which were calibrated with a standard pyranometer (SolData). Figure 4 shows the circuit diagram used for the calibration of minisolar panels (S1, S2, and S3) aiming them to use as reference cells for measuring input solar radiation. The procedures for the calibration are described below. First, a voltage divider across each of illuminated mini-solar panel (S1, S2, and S3) was made as shown in Figure 4. In case of S1 and S2, voltage dividers were made using two $100 \Omega$ resistors in series and a voltmeter (multi-meter) was connected across a $100 \Omega$ resistor. In the case of $\mathrm{S} 3$, three $100 \Omega$ resistors were used for making a voltage divider and a voltmeter was connected across $200 \Omega$ resistor (two $100 \Omega$ resistors in series). The $\mathrm{S} 1$, S2, S3 (each with a voltage divider circuit along), and the SolData were arranged in a horizontal position. They were illuminated in natural sunshine simultaneously. Voltages 
measured by volt meters connected across S1, S2, S3, and SolData were simultaneously recorded for several hours, then the correlation of the voltages produced across S1, S2, S3, and SolData were studied.

\section{RESULTS AND ANALYSIS}

The I-V curves obtained using the home-build instrument for mini-solar panels $\mathrm{S} 1, \mathrm{~S} 2$, and $\mathrm{S} 3$ are shown in figure 5. The I-V curves are good enough to calculate maximum output power density enabling us to calculate the efficiencies of the solar cells under test.

Table 1: Comparison of efficiencies of S1, S2, and S3 measured using the home-built solar cell testing instrument with their standard values of efficiencies.

\begin{tabular}{|l|l|l|l|}
\hline \multicolumn{4}{|c|}{ Efficiency (\%) } \\
\hline Mini solar panel & S1 & S2 & S3 \\
\hline Measured & 10.43 & 14.66 & 13.93 \\
\hline Standard & 16 & 16 & 16 \\
\hline
\end{tabular}

Table 1 shows comparison of efficiencies of S1, S2, and S3 measured with the home-build solar cell testing instrument with their standard values of efficiencies. The calculated efficiencies of the mini-panels except S1 are comparable with their standard values of the efficiencies ( 16\%) [11-13]. Slightly lower values of efficiencies of S3 and S2 compared with their standard values may be due to the degradation of efficiencies of the mini-solar panels. Errors in accurate measurements of the active areas of the solar panels and incident solar radiation intensities are probable other causes of the deviation. In case of panel S1, the manufacturing defect may be another cause of the lower measured value of the efficiency than its standard value of the efficiency.

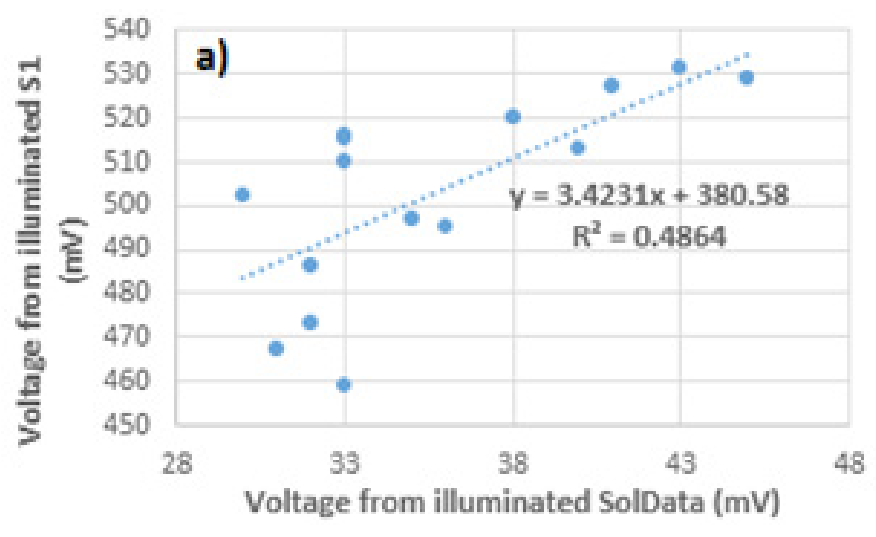

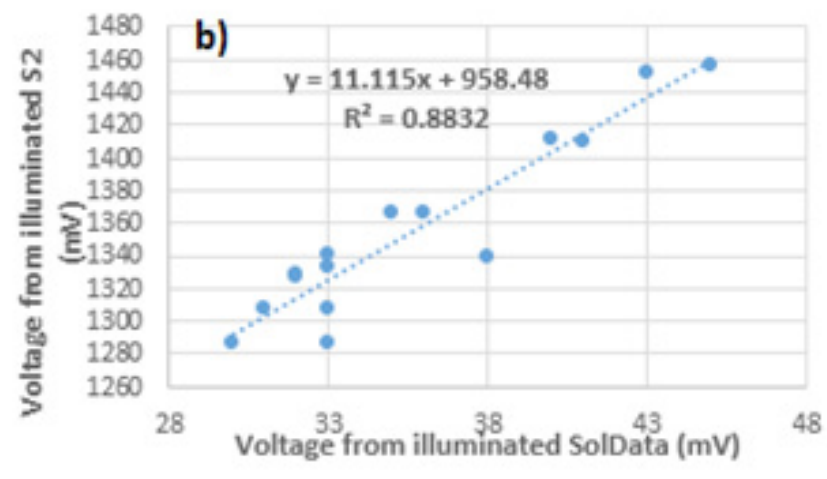

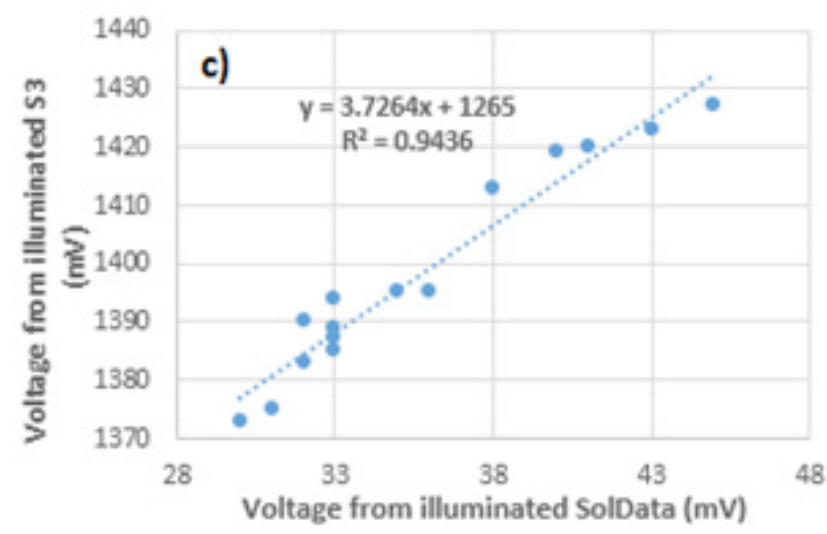

Figure 5: Linear fits of the voltages generated by illuminated SolData with corresponding voltages generated by a) illuminated mini-solar panels $S 1$, b) illuminated mini-solar panels $S 2$, and c) illuminated mini-solar panels $S 3$.

Figure 5 shows linear fits of the voltages generated by illuminated mini-solar panels $\mathrm{S}_{1}, \mathrm{~S}_{2}$, and $\mathrm{S}_{3}$ with the corresponding voltages generated by illuminated SolData. The correlations of voltages produced by $\mathrm{S} 1, \mathrm{~S} 2$, and $\mathrm{S} 3$ with SolData show that the values of $\mathrm{R}^{2}$ for $\mathrm{S} 3, \mathrm{~S} 2$, and $\mathrm{S} 1$ are $0.9436,0.8832$, and 0.4864 , respectively. This indicates that $\mathrm{S} 3$ can be the best candidate to replace the pyranometer for measurement of the intensity of the incident solar radiation on the device under test. Similarly, S2 can also serve the purpose with a good accuracy.

\section{Cost estimation of the home-made instrument for characterization of solar cells}

Major components used for the construction of the homemade instrument for characterization of solar cells are mini-solar panels (silicon solar cells), decade resistance box, and rheostats. Except the silicon solar cells, the other components of the instrument are generally available at undergraduate level physics laboratories. The total cost of the mini-solar cells (S1, S2, and S3) cost is less than US\$ 15 
[8-10]. In contrast, the cost of a solar simulator and a source meter used for characterization of solar cells in a standard laboratory exceeds more than a few thousands of dollars.

\section{CONCLUSIONS}

A home-made instrument for characterization of solar cells have been constructed. The instrument is aceeptable to use for testing solar cells. Also, mini-solar panels (silicon cells) can be used to measure solar radiation. The cost of home- made instrument is much lower than the standard instruments used for characterization of solar cells.

\section{ACKNOWLEDGMENTS}

This research work has been carried out at Bhaktapur Multiple Campus (BMC) and the author is thankful to the administration of BMC. Similarly, the author is grateful to Associate prof. and Assistant campus chief (Science) Sudarshana Shakya for her inspiration and support during the research work. Some of the components used in the research project were purchased from the research fund granted by Nepal Academy of Science and Technology (NAST). Thus, the author highly acknowledge NAST for the financial support. The author is also thankful to Mr. Pushkar Suwal, lecture of Kwopa Engineering College, and Mr. Anupan K.C.,teaching assistant (physics) of BMC.

\section{REFERENCES}

[1] Joshi, P., Xie, Y., Mwaura, J., Ropp, M., Galipeau, D. \& Qiao, Q., (2008). Dye-sensitized solar cells based on carbon counter electrode. In Proceedings of the 33rd IEEE Photovoltaic Specialists Conference (pp. 1-4). San Diego, CA, USA.

[2] Joshi, P., Yu, X., Ropp, M., Galipeau, D., Bailey, S., \& Qiao, Q. (2009). Dye-sensitized solar cells based on low cost nanoscale carbon $/ \mathrm{TiO}_{2}$ composite counter electrode.

Energy \& Environmental Science, 2, 426-429.

[3] O'Regan, B., \& Gratzel, M., (1991). A low-cost, highefficiency solar-cell based on dye-sensitized colloidal $\mathrm{TiO}_{2}$ films. Nature, 353, 737-740.

[4] Nelson, J. (2003). The physics of solar cells. London: Imperial College Press.

[5] Chawla, M. K. (n.d.). A step by step guide to selecting the "right" Solar Simulator for your solar cell testing application. Retrieved Jan 25, 2015, from http:// photoemission.com/techpapers/A\%20step $\% 20 b y \% 20$ step $\% 20$ guide $\% 20$ to $\% 20$ selecting $\% 20 a \% 20$ Solar $\% 20$ Simulator\%20Ver.\%203.pdf

[6] Keithley, (n.d.). I-V Characterization of Photovoltaic Cells and Panels Using the Keithley Model 2450 or Model 2460 SourceMeter ${ }^{\circledR}$ SMU Instrument. Retrieved Jan 25, 2015, from www.keithley.com/ data\%3Fasset\%3D57628

[7] Smestad, G. P., (1998). Education and solar conversion: Demonstrating electron transfer. Solar Energy Materials and Solar Cells, 55, 157-178, 1998.

[8] ebay (Aug 18, 2014), 4V x 125 mA. Mini Solar Panel epoxy encapsulated virtually indestructible $.5 \mathrm{~W}$. Retrieved Aug 18, 2014, from http://www.ebay.com/ $\mathrm{itm} /-/ 181375950371$

[9] ebay (Aug 18, 2014), 3Vx 70 mA. Mini Solar Panel epoxy encapsulated virtually indestructible $.2 W$. Retrieved Aug 18, 2014, from http://www.ebay.com/itm/3V-x-70mA-Mini-Solar-Panel-epoxy-encapsulated-virtuallyindestructible-2W-/171294706355?

[10] ebay (Aug 18,2014), 1Vx300mA. Mini Solar Panelepoxy encapsulated virtually indestructible $.3 \mathrm{~W}$. Retrieved Aug 18, 2014, from http://www.ebay.com/itm/1Vx-300-mA-Mini-Solar-Panel-epoxy-encapsulatedvirtually-indestructible-3W-/181301297192?"

[11] Ningbo Sunboy New Energy Co., Ltd. (Aug 18, 2014), SBE5050 1.5V 140mA Mini Solar Panel. Retrieved Aug 18, 2014, from http://nbsunboy. en.alibaba.com/product/847751069 -212617234/ SBE5050_1_5V_140mA_Mini_Solar_Panel.html

[12] Ningbo Sunboy New Energy Co., Ltd. (Aug 18, 2014), Polycrystalline 4V 100mA Mini Solar Panel. Retrieved Aug 18, 2014, from http://nbsunboy. en.alibaba.com/product/584349629-212617234/ Polycrystalline_4V_100mA_Mini_Solar_Panel.html

[13] Ningbo Sunboy New Energy Co., Ltd. (Aug 18, 2014), 3V160mA Mini Photovoltaic Module $75^{*} 60 \mathrm{~mm}$ (SBE7560). Retrieved Aug 18, 2014, from http://sunboy2011.en.made-in- china.com/ product/dqDnZBRKpNVv/China-3V160mA-MiniPhotovoltaic-Module-75-60mm-SBE7560-.html 